\title{
Synthesis, characterization and application of a bio-derived ZnO nano- powder from spinacia oleracea leaf extract for the removal of BOD and COD from tannery wastewater
}

\author{
Danauta Paschal Feka ${ }^{a}$, , Amaya Jobin Habila ${ }^{a}$, Kyauta Francis ${ }^{b}$, James Dama Habilab, Moses Yohanna \\ Bammai
}

a Department of Science Laboratory Technology, Nigerian Institute of Leather and Science Technology, Zaria, Nigeria; ${ }^{b}$ Department of Chemistry, Ahmadu Bello University, Zaria, Nigeria; ' Department of Chemistry, Center for Food Technology and Research, Benue State University, Makurdi, Nigeria.

\begin{abstract}
Biochemical Oxygen Demand (BOD) and Chemical Oxygen Demand (COD) as biological and chemical pollutants of wastewater are renowned environmental problems. A study of the performance of BOD and COD degradation via adsorption was undertaken using Bio-derived $\mathrm{ZnO}$ nanopowder (ZnO-NP), synthesized using leaf extract of Spinacia oleracea, and $\mathrm{Zn}\left(\mathrm{NO}_{3}\right)_{2}$ at $500{ }^{\circ} \mathrm{C}$, following a simple and green approach. XRD, SEM, FTIR, EDS and BET analysis were used to characterize the nano-adsorbent. EDS spectrum recorded elemental weight compositions of $67.33 \%$ and $32.67 \%$ for $\mathrm{Zn}$ and $\mathrm{O}$, while the FTIR absorption peaks revealed the presence of $\mathrm{Zn}-\mathrm{O}-\mathrm{H}$ and $\mathrm{Zn}-\mathrm{O}$. Surface area that $\mathrm{ZnO}$ nanopowder is better applied as BOD reductants over COD for spent tan liquor.

\section{HIGHLIGHTS}

- EDS reveals the elemental weight of $67.33 \%$ and $32.67 \%$ for $\mathrm{Zn}$ and O, respectively.

- The ZnO-NP exhibited a stable photocurrent density.

- ZnO-NP recorded BOD removal efficiency of 81.5, 83.4, 85.8, 90.3 and $90.8 \%$.

- Removal efficiency of COD is low (12 - $50 \%$ ) but improves progressively with increasing contact time.
\end{abstract}

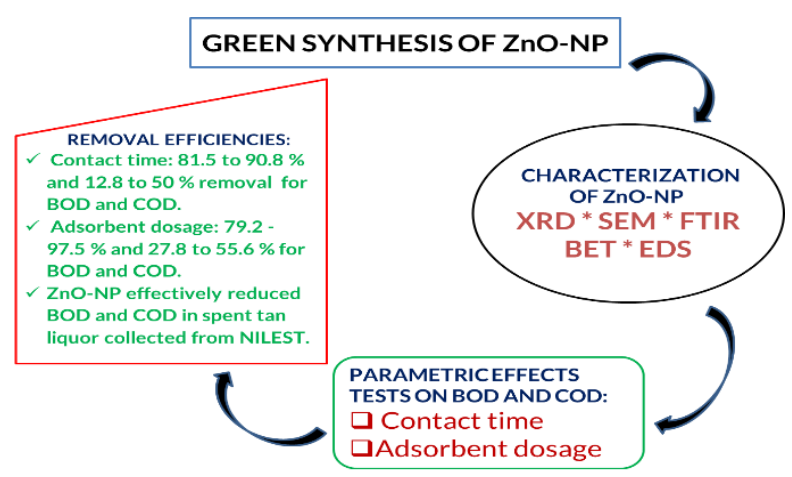
analysis revealed the mesoporous structure of the ZnO-NPs. The reduction efficiency of the ZnO-NPs was evaluated in the presence of raw tannery wastewater by application of treatment time and adsorbent dosage as parametric factors; results obtained were compared to environmental regulatory limits (WHO and NESREA). Contact times reported removal efficiencies of $81.5-90.8 \%$ and $12.8-50 \%$ for BOD and COD, while adsorbent dosage-influenced BOD and COD removal at an optimum contact time of 30 minutes was found to be $79.2-97.5 \%$ and 27.8 to $55.6 \%$ respectively. This study reveals

\author{
Article History: \\ Received:30 ${ }^{\text {th }}$ August, 2020 \\ Accepted: $12^{\text {th }}$ February, 2021 \\ Available online: $29^{\text {th }}$ April, 2021 \\ Keywords: \\ ZnO-nanopowders; Bio-derived; Bio-sorbents; \\ Tan liquor; Green synthesis
}

\section{Introduction}

In recent times, the field of adsorption studies has witnessed additions of a variety of efficient, eco-friendly and cost-effective nano-materials, that finds application in the decontamination of industrial and domestic liquid wastes (Theron et al., 2008; Gupta et al., 2015; Shamsizadeh et al., 2014; Kyzas and Matis et al., 2015). Treatment of wastewater and drinking water can reduce contamination concerns (Ferroudj et al., 2013); however, existing traditional methods of treatment in practice are not efficient enough to completely remove emerging contaminants (Jiuhui, 2008; Ferroudj et al., 2013; Bali et al., 2003), thus, the emphasis on a more efficient, cheaper and powerful green technology for the treatment of municipal and industrial wastewaters (Jarvis, 2006; Ferroudj et al., 2013). A variety of efficient, ecofriendly and cost-effective nano-materials with unique functionalities for potential decontamination of industrial effluents, surface water, groundwater and drinking water have been employed in wastewater treatment (Gupta et al.,

* CONTACT: D. P. Feka; fekapaschal@yahoo.com; Nigerian Institute of Leather and Science Technology, Zaria, Nigeria 
2015; Theron et al., 2008). From documented evidence, nano-technology has a proven ability to remediate wastewaters (Zare et al., 2013; Sadegh et al., 2014), because structurally, they are components with a dimensional size of at least below $100 \mathrm{~nm}$ (Amin et al., 2014). BOD and COD levels in wastewaters are serious environmental concerns and could present detrimental effects especially when their presence exceeds environmental standards (Davi, 2009; Ramasami et al., 2015)

Nanomaterials exist in a variety of forms, including nano-wires, nano-tubes, films, particles, quantum dots and colloids, all having excellent liquid treatment potential (Edelstein and Cammaratra, 1998; Lubick and Betts, 2008; Dutta and Maji, 2014). Nano-adsorbent can be produced using atoms of elements that are chemically active and having high adsorption capacity on the surface of the nanomaterial (Kyzas and Matis, 2015). Activated carbon, silica, clay materials, metal oxides and modified compounds in the form of composites are examples of nano-adsorbents employed for wastewater treatment (El-Saliby et al., 2008).

The use of metal oxide-based nanoparticles as adsorbents is gaining recognition in environmental sciences. Researches on $\mathrm{ZnO}$ and $\mathrm{CuO}$ based nanoparticles for photocatalytic and biological activities have also been published (Saikia et al., 2015; Tamuly et al., 2014). Oladipo et al., (2017), reported the synthesis of a bio-derived MgO nonpowder and applied it in the reductive treatment of BOD and COD in tannery wastewater; with results showing a 93.5\% and $96.9 \%$ removal. Because industrial activities vary, so also will the wastes they generate (both physical and chemical parameters), with pollution levels rising beyond prescribed levels. Untreated effluents when released into receiving water bodies (rivers, lakes, ponds, etc.), are a major contributor to water pollution (Rehman and Anjum, 2010). Spent Tan liquor from leather industries characteristically, in addition to metal contaminants contains high concentrations of organic particles and sediments, accounting for its high BOD (Biological Oxygen Demand) and COD (Chemical Oxygen Demand) levels (Ramasami et al., 2015).

The contaminant parameter, BOD, is the quantity of oxygen consumed by organisms in breaking down liquid wastes or the amount of oxygen available to the organism to carry out its metabolic activities. COD on the other hand indicates the extent of organic matter contamination of a water system, and COD is always higher than BOD. COD is useful for understanding the overall organic load of a receiving water body (APHA, 1998; Sawyer et al., 2000).

Tannery wastewater is a major source of environmental pollution, generating high organic pollutants (BOD and COD) at excessively high concentrations. BOD and COD are major organic pollution indicators of wastewater generated at various processing stages of the leather tanning process (e.g. soaking, unhairing/liming, lime fleshing, deliming/bating, degreasing, pickling/tanning, sammying, retanning, dyeing and fatliqouring). Traditional materials and treatment technologies (reverse osmosis (RO), oxidation, activated sludge, nanofiltration (NF), and activated carbon) are not adequate enough in the removal of huge amounts of organic micropollutants. The demand for organic micropollutants removal is the motivation for the research into economically feasible and environmentally stable water/wastewater treatment technology to meeting the environmental water quality standards. This study aims to synthesize and test the capacity of a biodegradable adsorbent (Zinc Oxide) in the remediative treatment of BOD and COD polluted spent tan liquor derived from the Nigerian Institute of Leather and Science Technology (NILEST) Zaria.

\section{Materials and methods}

\subsection{Materials}

Analytical grade chemicals were used without further purification in this study. Zinc nitrate hexahydrate $(99.999 \%$ trace metals basis) was procured from Thomas Scientific (Swedesboro, NJ), leaves of Spinacia oleracea from Samaru, Nigeria. Untreated tannery effluent was collected from the tannery at the Nigerian Institute of Leather and Science Technology, Zaria, Nigeria. The equipment used are listed below: FTIR (PerkinElmer 1750) was used to measure the infrared region of the electromagnetic radiation spectrum in order to identify chemical bonds and functional groups in the sample. BET analyzer (Quantachrome Nova 2000e) was used to measure the surface area of the adsorbent. Scanning electron microscope (JEM-ARM200F) was used to study the surface morphology and estimate elemental components of the adsorbent.

\subsection{Collection and preparation of leave extract}

Fresh leaves of Spinacia oleracea were obtained from the Samaru market in Zaria, Kaduna State. The leaves were washed thoroughly with tap water to remove sand and other solid particles and then rinsed severally with distilled water, chopped into tiny bits, air-dried for 12 days, grounded to powder using mortar and pestle. A-50 g of powdered leaves was weighed out and added to $400 \mathrm{~mL}$ of distilled water in a $1000 \mathrm{~mL}$ conical flask and stirred under heat at $80^{\circ} \mathrm{C}$ for 30 minutes. The extract was mixed and centrifuged for 10 minutes and then filtered, the filtrate was kept in the refrigerator for use in the synthesis of ZnO-NP.

\subsubsection{Green synthesis of $\mathrm{ZnO}$ nanopowders}

An aliquot of $150 \mathrm{~mL}$ of the aqueous plant extract was mixed with $20 \mathrm{~mL}$ of $\mathrm{Zn}\left(\mathrm{NO}_{3}\right)_{2} \cdot 6 \mathrm{H}_{2} \mathrm{O}$ in a $400 \mathrm{~mL}$ conical flask. The mixture was vigorously stirred for 20 minutes at ambient temperature, forming milky precipitates and were collected by centrifugation. The precipitates were washed with ethanol, rinsed with distilled water, and dried at $90{ }^{\circ} \mathrm{C}$ for 3 hours. The dried precipitate powder was heated in an oven (Isco S4A00005-MICRA9S) at $500^{\circ} \mathrm{C}$ for 2 hours to form ZnO nanopowder. 


\subsubsection{Characterization of $\mathrm{ZnO}$ nanopowders (ZnO-NPs)}

The spinacia oleracea leaf was determined to be rich in chloride, potassium and carbonate ions after titration and elementary analyses. The ions present in the leaf $\left(\mathrm{Na}^{+}, \mathrm{CO}_{3}{ }^{2-}\right.$ , $\mathrm{K}^{+}$) react with $\mathrm{Zn}\left(\mathrm{NO}_{3}\right)_{2} \cdot 6 \mathrm{H}_{2} \mathrm{O}$ to form $\mathrm{Zn}(\mathrm{OH})_{2}$ and the product was subjected to heat treatment at $500^{\circ} \mathrm{C}$ to form ZnO NPs.

\subsection{Collection of tannery effluent}

The tannery effluent was collected by spot (grab) sampling method as detailed elsewhere (UNIDO, 2016). Collected wastewater was filtered and stored in a cooling set, at freezing temperature (below $4{ }^{\circ} \mathrm{C}$ ) till use.

\subsubsection{Sorptive treatment experiment via batch and fixed-bed system}

The tannery wastewater was treated according to the sorptive remediation method by Oladipo et al., (2017). The sorption experiment was carried out at ambient temperature under different experimental conditions (contact time and adsorbent dosage). Effect of contact time was achieved by contacting $50.0 \mathrm{mg}$ of ZnO-NPs with $50 \mathrm{~mL}$ tannery wastewater of initial BOD of $91.8 \mathrm{mg} / \mathrm{L}$ and COD of $576 \mathrm{mg} / \mathrm{L}$. The experiment was carried out in sealed conical flasks at 20 min interval between 20 to 100 minutes per experiment batch. Samples were drawn every 20 minutes, filtered and analyzed. Effect of adsorbent dosage was deduced at different nanopowder dosages (between 20-100 $\mathrm{mg} / \mathrm{L})$, at $\mathrm{pH} 12$ ( $\mathrm{pH}$ of the tan liquor). The above experimental procedures were carried out in triplicate from which the mean result was calculated. The percentage removal of COD and BOD concentrations were validated by using the equations:

$$
\begin{aligned}
& R(\%)=\frac{(B O D i \times V i)-(B O D f \times V f)}{B O D i \times V i} \times 100 \\
& R(\%)=\frac{(\operatorname{COD} i \times V i)-(\operatorname{COD} f \times V f)}{\operatorname{COD} i \times V i} \times 100
\end{aligned}
$$

Where: $B O D i, C O D i, B O D f$ and $C O D f$ are the initial and final concentrations at a given time, respectively. $V i$ and $V f$ are the volumes of the untreated and treated wastewater solutions, respectively.

\subsection{Determination of Organic Waste Contaminants (BOD and COD)}

The BOD and COD of untreated and treated effluents were analyzed according to the standard methods of APHA (1998). In the BOD analysis, dilutions were prepared as appropriate, for the sample(s) to be tested. The diluted samples were transferred to corresponding glass stoppered BOD bottle(s), heated to $20^{\circ} \mathrm{C}$, then the DO of the sample was measured in $\mathrm{mg} / \mathrm{L}$ using a DO meter and electrode. An appropriate quantity of nitrification inhibitor was added to the sample, and the bottle was again stoppered and incubated. The incubated samples were again tested for DO after the fifth day. The final DO reading was subtracted from the initial DO reading, and the result was the BOD concentration $(\mathrm{mg} / \mathrm{L})$. The $\mathrm{BOD}_{5}$ was determined using: $B O D_{5}=D O_{0}-D_{5}$.

Before starting COD analysis, a series of known standards are prepared using potassium hydrogen phthalate (KHP) in the high range of 100,250, 500 and 1000 $\mathrm{mg} / \mathrm{L}$. A COD reactor/heating $\left(150{ }^{\circ} \mathrm{C}\right)$ block and a colourimeter were turned on so that both instruments are allowed to stabilize. Seven pre-prepared high-range (20 $1500 \mathrm{mg} / \mathrm{L}$ ) vials were selected for the test and labelled as blank (1 vial), standard (4 vials) and wastewater (2 vials), and to each vail, $2 \mathrm{~mL}$ of deionized water, KHP standard and tanliquor were added, respectively, mixed well and placed inside the reactor block for $2 \mathrm{~h}$. After two hours, the vials were transferred to a cooling rack for about 15 minutes before colourimetric measurement. The colourimeter was set and calibrated as per the specific instructions for that unit (proper wavelength for blank and standards). Each vial was placed in the unit and the COD concentration was noted.

\section{Results and discussion}

The result of $X$-Ray Diffraction as presented in Fig. 1, the ZnO-NP was characterized by powder X-ray diffraction (equipped with $\mathrm{Cu}$ Ka radiation (1.5406 $\AA$ ) and a graphite monochromator operated at $40 \mathrm{Kv}$ and $30 \mathrm{~mA}$ in BraggBrentano geometry. The XRD spectra were collected in the $2 \theta$ range between $20^{\circ}$ and $80^{\circ}$ using a step-scan mode of $0.05^{\circ}(2 \theta)$. Following synthesis, X-Ray diffractogram of the ZnO-NP exhibits high crystalline nature, with sharp and intense peaks. The intense diffraction peaks appeared at $31.9^{\circ}, 34.8^{\circ}, 36.6^{\circ}, 48.3^{\circ}, 56.9^{\circ}, 63.9^{\circ}, 67.9^{\circ}, 69.2^{\circ}$, which corresponded to the (100), (002), (101), (102), (110), (103), (112) and (201) planes, respectively, and matched well with JCPDS card no. 75-1533 for the hexagonal wurtzite ZnO closely packed structure ( $h c p$ structure). A definite line broadening of the XRD peaks indicates that the prepared material consists of particles in the nanoscale range (Talam et al., 2012).

The crystallite size was calculated using the Debye Scherrer formula: $D=0.9 \lambda / \beta \cos \theta$, where $D$ is the average crystallite size, $\lambda$ is the wavelength of X-rays and $\beta$ is the full width at half maximum for the most intense peak at 101 (Fig.

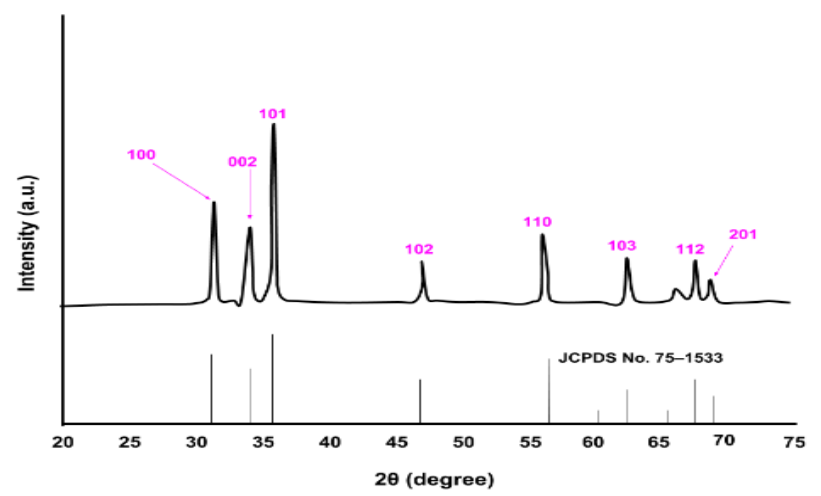

Fig. 1. X-ray diffraction (XRD) pattern of ZnO-NP. 
1). The crystallite size was found to be $\sim 9 \mathrm{~nm}$. Crystallite size generally corresponds to the coherent volume in the material for the respective diffraction peak, it may also correspond to the grain size of a powdered sample, or a measure of the thickness of polycrystalline thin film or bulk material (Gubicza, 2012). The average size of ZnO-NP calculated was $8 \mathrm{~nm}$ which is in agreement with the acceptable range of 4-8 $\mathrm{nm}$ derived from the Scherrer equation and agrees with findings by Deepracha et al., (2019). Hydrogen storage properties of nanomaterials were investigated by Andrew, (2019), the outcome shows the smaller the crystallite sizes, the reduced diffusion path of hydrogen enhance the sorption kinetics significantly.

The specific surface area of the synthesized ZnO-NP was examined using the Brunauer-Emmett-Teller (BET) method employing a BET analyzer as displayed in Figures 2 and 3 (a, b). Many of the unique, intrinsic properties associated with nanomaterials arise from the large surface-to-volume ratio of these exceptionally small materials. Surface area properties may also be relatable to environmental fate and hazard implications; therefore, accurately measuring surface area is extremely important for material characterization. The most commonly used method of measuring the surface area of nanomaterials is the Brunnauer-Emmett-Teller (BET) surface adsorption method (Brame and Griggs, 2016).

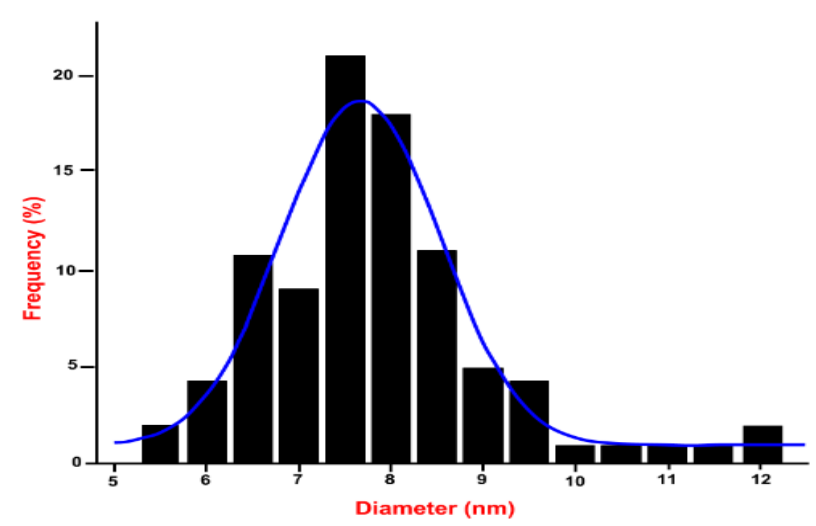

Fig. 2. Size distribution of ZnO-NP.

From Fig. 3, the pore size distributions indicated that $\mathrm{ZnO}$ presents a relatively narrow distribution ranging from $5 \mathrm{~nm}$ to $12 \mathrm{~nm}$. Taking into account the morphology of the material revealed by the SEM micrograph, the small pores would represent the intra nanoparticles pores. The BET surface area of the synthesized $\mathrm{ZnO}$ was measured to be $39.8 \mathrm{~m}^{2} / \mathrm{g}$. The pore size distribution curve was determined using Barrett, Joyner, and Halenda (BJH) methods as shown in Fig. 3 (b). The BJH average pore size, total pore volume and pore surface area of $\mathrm{ZnO}$ were recorded as $18.12 \mathrm{~nm}$, $0.039 \mathrm{~cm}^{3} / \mathrm{g}$ and $11.67 \mathrm{~m}^{2} / \mathrm{g}$, respectively. The sample exhibited isotherm of type IV (BDDT classification) with hysteresis loops of type $\mathrm{H} 3$ at relative pressure, indicating the presence of mesoporous structure, similarly as obtained
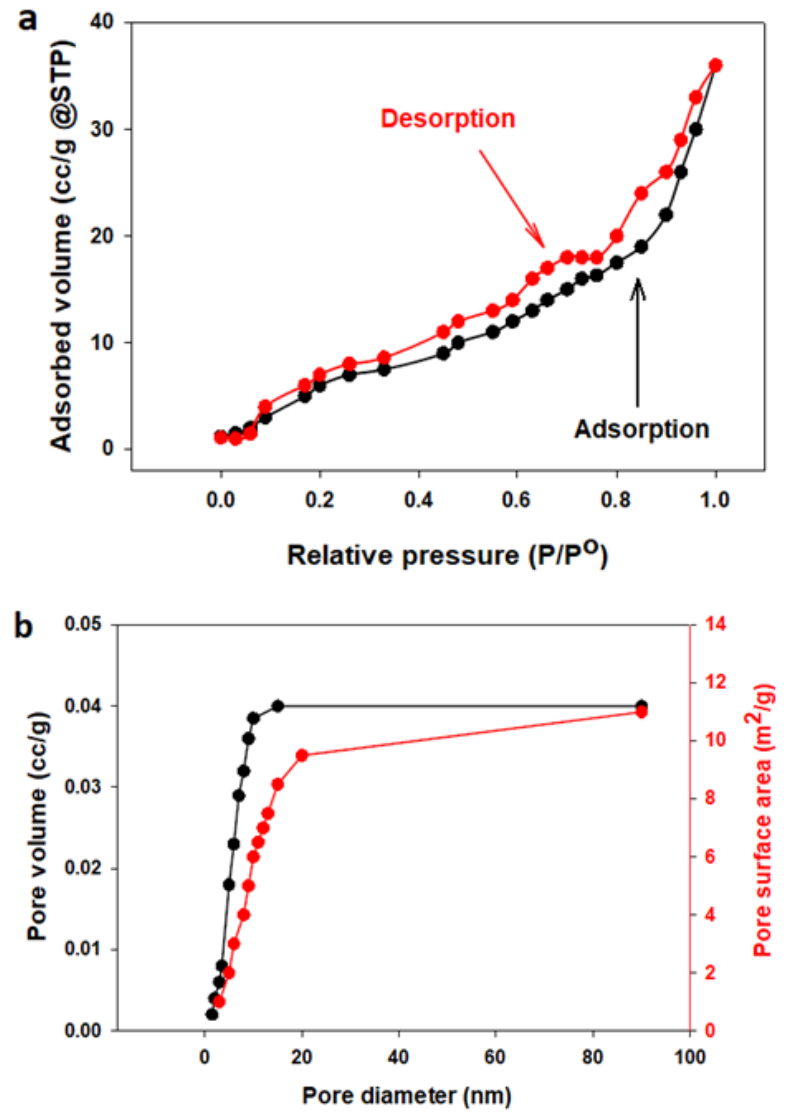

Fig. 3. Surface area (a) and Pore features (b) of the $\mathrm{ZnO}$.

for $\mathrm{TiO}_{2}$ by Wei et al., (2013). The BET surface area of the prepared $\mathrm{ZnO}$ nanoparticles was $11.67 \mathrm{~m}^{2} / \mathrm{g}$ and the BET surface area of commercial P25 was $50 \mathrm{~m}^{2} / \mathrm{g}$. A larger surface area provides more surface active sites for the adsorption of the reactive molecules, which leads the photocatalytic process to be more efficient. We can draw the conclusion that the nanoparticles prepared by us might have good photocatalytic activities.

Energy dispersion spectrum (EDS) reveals elemental weight compositions of $67.33 \%$ and $32.67 \%$ for $\mathrm{Zn}$ and $\mathrm{O}$, respectively (Fig. 4), which are equivalent to 33.52:66.48 in atomic percentage. The prominence of $\mathrm{Zn}$ and $\mathrm{O}$ peaks in the spectrum confirm the formation of $\mathrm{ZnO}$. The absence of

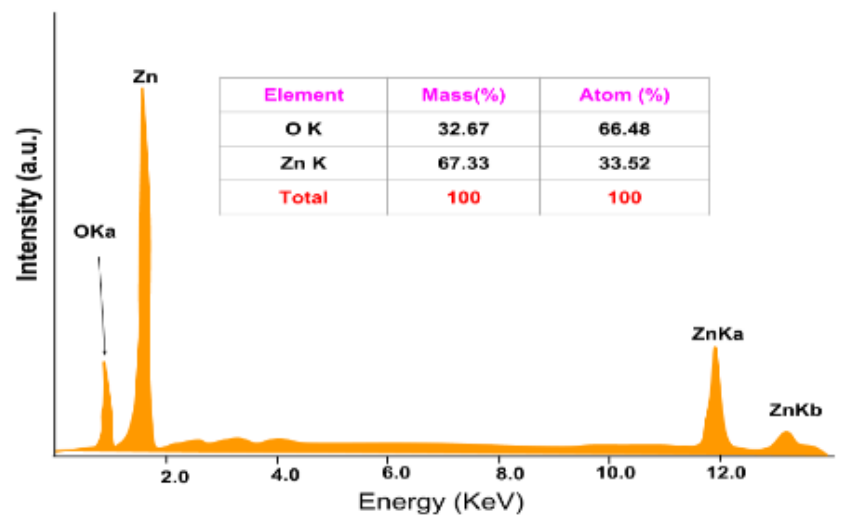

Fig. 4: EDS spectrum of ZnO-NPs. 
any other elemental peak indicates the high purity of prepared samples. The nanoparticles appear to be spherical in shape with an average size of 10-130 nm. Recent studies have shown the application of chemical precipitation, adsorption, oxidation-reduction, evaporation, ionic exchange, electrochemical treatment, and membrane separation techniques in metal extraction from wastewaters (Krishna, 2018). Removal of toxic pollutants by adsorption on metal oxides has shown immense potential. Metal oxides possess large surface areas, porous structures, large number of active sites, thermal stability, easy recovery and low toxicity; they have shown outstanding performance for the adsorption and remediation of contaminants (Nagpal and Kakkar, 2018).

Textural morphology was confirmed by SEM micrograph as shown in Fig. 5. The micrograph shows that $\mathrm{ZnO}-\mathrm{NPs}$ exhibited non-uniform agglomerated particles of lump-like spherical morphology. Owing to their size and higher surface area to volume ratio, nanomaterials possess some unique properties as compared to their bulk counterpart (e.g. charcoal), and the large surface area of these materials make them effective adsorbents in pollution remediation (Sarma et al., 2019). Fig. 3 further revealed well-developed mesopores (pores between 2 and $50 \mathrm{~nm}$ ), and an easily modifiable surface, producing a large number of agglomerates of nanoparticles in nanocomposites (Rodríguez et al., 2020; Ashraf et al., 2018).

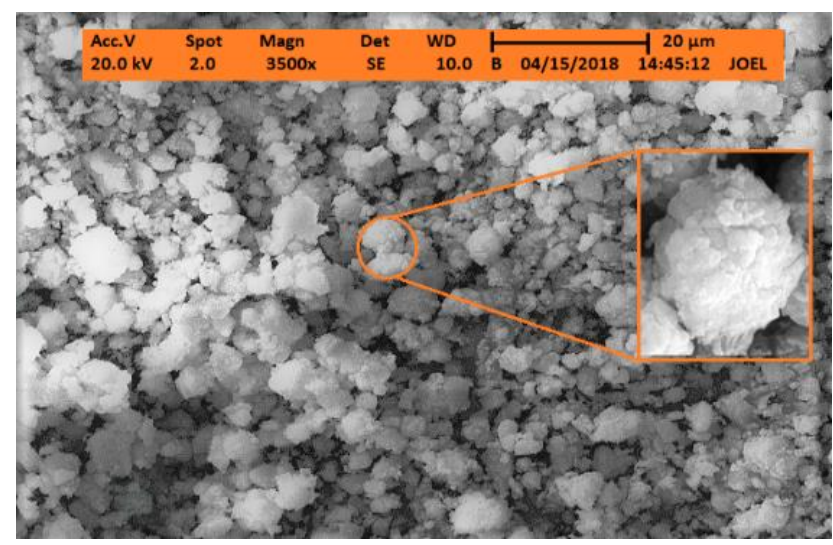

Fig. 5. SEM micrograph of ZnO-NP.

Fig. 6 is the graph of the photocatalytic behaviour of the adsorbent. Photocurrent response was recorded as a fast growth in which decay was visible. The ZnO-NP exhibited a stable photocurrent density of $3.35 \mu \mathrm{A} / \mathrm{cm}^{2}$; directly confirming that the adsorbent is capable of exhibiting high recombination efficiency of photogenerated electron-hole pairs. ZnO has been shown to offer multifarious advantages such as chemical-physical stability, low cost, and environmental friendliness (Deng et al, 2019). The photocurrent response is responsible for enhancing interfacial charge-transfer kinetics between the ZnO-NP and the adsorbate in the presence of wastewater, even though this may prove more effective in the removal of metals from

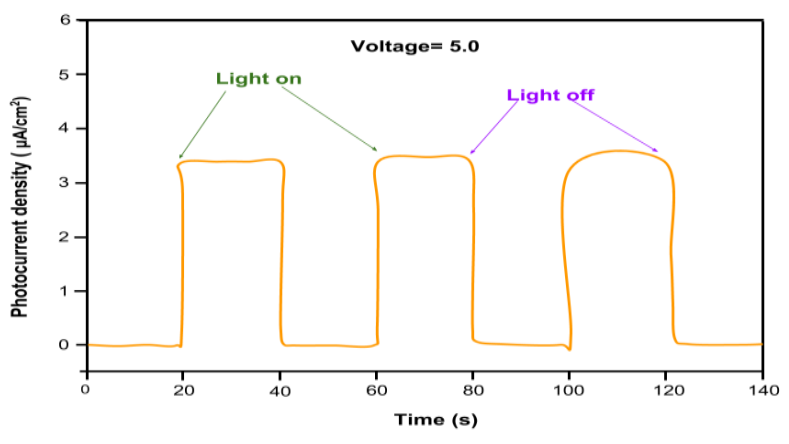

Fig. 6. Photocurrent response of ZnO-NP.

liquid wastes (Chandrasekharan and Kamat, 2000; Liu et al., 2018).

FTIR study was evaluated at wavelengths of $350-4000$ $\mathrm{cm}^{-1}$, absorption band appearing at region $3330-3600 \mathrm{~cm}^{-1}$ is likely due to the $\mathrm{O}-\mathrm{H}$ stretching of water molecule. The sharp bending vibration peak at 1522 and $1511 \mathrm{~cm}^{-1}$ was attributed to $\mathrm{O}-\mathrm{H}$ stretching vibration of water. These vibrations represent the bound water on $\mathrm{ZnO}$ nanoparticles as displayed in Fig. 7. The sharp peak at $1486 \mathrm{~cm}^{-1}$ corresponded to the $\mathrm{O}-\mathrm{H}$ stretching vibration (Mousavi et al., 2015). The absorption peaks at 968,602 and $439 \mathrm{~cm}^{-1}$ revealed the presence of $\mathrm{Zn}-\mathrm{O}-\mathrm{H}$ and $\mathrm{Zn}-\mathrm{O}$ stretching vibration (Kansal et al., 2013).

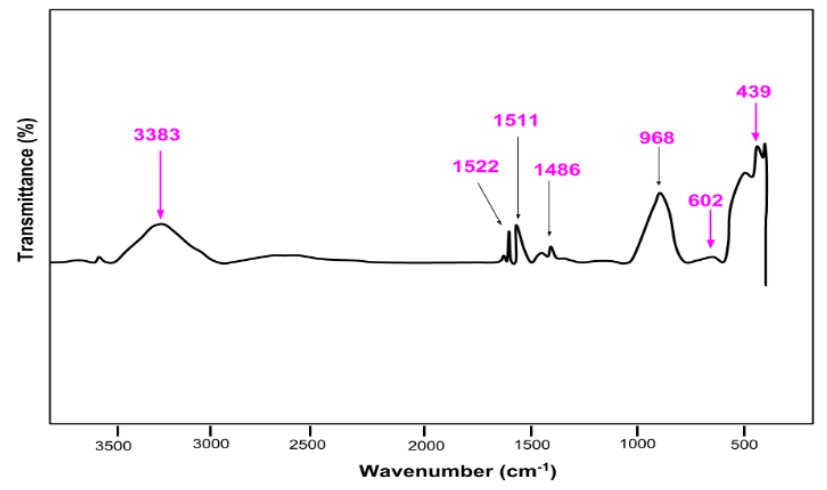

Fig. 7. FTIR spectra of ZnO-NP.

\subsection{Comparative adsorptive removal of $B O D$ and $C O D$ from NILEST tannery}

The effect of adsorptive treatment time is presented in Tables 1 and 2. An initial concentration of $91.8 \mathrm{mg} / \mathrm{L}$ was documented for BOD at varying contact times of $20,40,60$, 80 and 100 minutes. The BOD concentrations recorded after treatment for corresponding contact times were 17.0, 15.2, $13.0,8.9$ and $8.4 \mathrm{mg} / \mathrm{L}$. The results recorded were below the WHO (world health organization) and NESREA (National Environmental Standards and Regulations Enforcement Agency) environmental limits of $30 \mathrm{mg} / \mathrm{L}$. The percentage removal efficiency calculated and reported for the respective BOD concentrations was $81.5,83.4,85.8,90.3$ and $90.8 \%$. This is in close agreement with findings by Devi et al., (2008) on the reduction of chemical oxygen demand 
(COD) and biological oxygen demand (BOD) of wastewater from coffee processing plant using activated carbon made from Avacado Peels with $99.02 \%$ and $99.35 \%$ removal at optimum operating conditions.

Table 1. Effect of treatment time on $B O D$ and $C O D$ removal at $\mathrm{pH} 12$ using $50.0 \mathrm{mg}$ of $\mathrm{ZnO}-\mathrm{NP}$.

\begin{tabular}{lllll}
\hline $\begin{array}{l}\text { Contact } \\
\text { time } \\
(\mathrm{min})\end{array}$ & $\begin{array}{l}\text { BOD } \\
\text { Concentration } \\
(\mathrm{mg} / \mathrm{L})\end{array}$ & $\begin{array}{l}\% \\
\text { Removal }\end{array}$ & $\begin{array}{l}\text { COD } \\
\text { Concentration } \\
(\mathrm{mg} / \mathrm{L})\end{array}$ & $\begin{array}{l}\% \\
\text { Removal }\end{array}$ \\
\hline 20 & $17.0 \pm 0.10$ & $81.5 \pm 0.01$ & $502 \pm 0.08$ & $12.8 \pm 0.01$ \\
40 & $15.20 \pm 0.10$ & $83.4 \pm 0.02$ & $480 \pm 0.02$ & $16.7 \pm 0.01$ \\
60 & $13.0 \pm 0.01$ & $85.8 \pm 0.02$ & $416 \pm 0.11$ & $27.8 \pm 0.02$ \\
80 & $8.90 \pm 0.08$ & $90.3 \pm 0.30$ & $352 \pm 0.01$ & $38.9 \pm 0.08$ \\
100 & $8.40 \pm 0.01$ & $90.8 \pm 0.11$ & $288 \pm 0.01$ & $50.0 \pm 0.01$ \\
\hline
\end{tabular}

The lowest percentage removal for COD was $12.8 \%$, and highest was $50 \%$. The removal of COD was mostly low (below $50 \%$ ) but improves progressively with increasing contact time. At 20 minutes intervals, COD reduction from an initial concentration of $576 \mathrm{mg} / \mathrm{L}$ decreased to 502,480 ,
416, 352 and finally $288 \mathrm{mg} / \mathrm{L}$; corresponding to contact times of 20, 4060,80 and 100 minutes respectively. Result reveals $\mathrm{ZnO}$-NP has less removal preference for COD over BOD.

Results presented in Table 2 shows that increasing adsorbent dosage will influence BOD and COD removal efficiency at an optimum contact time of 30 minutes. The percentage removal of 79.2, 83.7, 88.6, 93.9 and $97.5 \%$ on application of corresponding adsorbent masses of 20, 40, 60,80 and $100 \mathrm{mg}$, for BOD at an initial concentration of $91.8 \mathrm{mg} / \mathrm{L}$ was studied (Table 2), with the result presenting the effect of adsorbent dosage on COD removal; percentage removal efficiency recorded ranged from a minimum of 27.8 to a maximum of $55.6 \%$ at an initial concentration of $576 \mathrm{mg} / \mathrm{L}$.

The decrease in BOD and COD with increasing adsorbent dose is ascribed to an increase in adsorption sites and surface areas of the ZnO-NPs, which led to an enhancement performance in the removal of the organic ions, due to the higher frequency of contact with the adsorbent, this is consistent with studies carried out by Singh et al., (2013); Kumar, et al., (2013), and Oladipo et al., (2017). In a study, nanostructured $\mathrm{ZnO}$ semiconductor films were used for the degradation of organic contaminants (4-chlorocatechol) to a great effect.

Table 2. Effect of adsorbent dosage on BOD and COD removal at pH 12 and contact time of 30 min.

\begin{tabular}{|c|c|c|c|c|c|c|}
\hline \multirow{2}{*}{$\begin{array}{l}\text { Mass of ZnO- } \\
\text { NP (mg) }\end{array}$} & \multicolumn{2}{|c|}{ BOD treatment $(\mathrm{mg} / \mathrm{L})$} & \multirow{2}{*}{$\%$ Removal } & \multicolumn{2}{|c|}{ COD treatment (mg/L) } & \multirow{2}{*}{ \% Remova } \\
\hline & Before & After & & Before & After & \\
\hline 20 & & $19.1 \pm 0.01$ & $79.2 \pm 0.11$ & & $416 \pm 0.01$ & $27.8 \pm 0.09$ \\
\hline 40 & & $15.0 \pm 0.01$ & $83.7 \pm 0.07$ & & $384 \pm 0.12$ & $33.3 \pm 0.01$ \\
\hline 60 & $91.8 \pm 0.10$ & $10.5 \pm 0.05$ & $88.6 \pm 0.11$ & $576 \pm 0.01$ & $320 \pm 0.09$ & $44.4 \pm 0.01$ \\
\hline 80 & & $5.6 \pm 0.01$ & $93.9 \pm 0.01$ & & $288 \pm 0.01$ & $50.0 \pm 0.06$ \\
\hline 100 & & $2.3 \pm 0.09$ & $97.5 \pm 0.03$ & & $256 \pm 0.11$ & $55.6 \pm 0.01$ \\
\hline
\end{tabular}

\section{Conclusion}

This work has demonstrated the feasibility of synthesizing an eco-friendly adsorbent from aqueous extracts of the leaves of Spinacia oleracea and its application in reducing $B O D$ and $C O D$ from tan liquor. Characteristics for the adsorptive potential of the adsorbent were evaluated and documented as having properties favourable for the removal of BOD and COD from tannery wastewaters. Application of ZnO-NP as an adsorbent for BOD and COD removal and its resultant efficiency shows great potentials while indicating the economic viability of diversifying the usability of Spinacia oleracea. BOD removal was more effective over COD, therefore $\mathrm{ZnO}-\mathrm{NP}$ is best efficient in the removal of BOD from tannery wastewater. Results also implicate the NILEST tannery wastewater as a large reservoir of biological and chemical oxygen depletant whose concentration does not satisfy the legal ranges for investigated parameters.

\section{CRediT authorship contribution statement}

D. P. Feka: Conceptualization, Methodology, Resources, Writing - original draft, Writing - review \& editing. A. J. Habila: Methodology, Writing - review \& editing. K. Francis: 
Methodology, Data curation, Software. J. D. Habila: Writing review \& editing, Resources. M. Y. Bammai: Writing - review \& editing

\section{Declaration of competing interest}

The authors declare that they have no known competing financial interests or personal relationships that could have appeared to influence the work reported in this paper.

\section{Acknowledgement}

The authors wish to acknowledge the Nigerian Institute of Leather and Science Technology (NILEST) Zaria, Nigeria for providing the spent tan liquor and laboratory facility to carry out a part of the work at no financial cost to the researchers.

\section{References}

Amin, M. T., Alazba, A. A., \& Manzoor, U. (2014). A review of removal of pollutants from water/wastewater using different types of nanomaterials. Advances in Materials Science and Engineering, 2014. https://doi.org/10.1155/2014/825910

Andrew R. (2019). Processing, structure, and properties of alumina ceramics, Woodhead Publishing Series in Biomaterials, Alumina Ceramics, Woodhead Publishing, Pgs 71-121.

APHA, AWWA, WEF. (1998). Standard methods for examination of water and waste water. American Public Health Association, Washington, D.C.

Ashraf, M. A., Peng, W., Zare, Y., \& Rhee, K. Y. (2018). Effects of size and aggregation/agglomeration of nanoparticles on the interfacial/interphase properties and tensile strength of polymer nanocomposites. Nanoscale research letters, 13(1), 1-7. https://doi.org/10.1186/s11671-018-2624-0

Bali, U., Çatalkaya, E. Ç., \& Şengül, F. (2003). Photochemical degradation and mineralization of phenol: a comparative study. Journal of Environmental Science and Health, Part A, 38(10), 2259-2275. https://doi.org/10.1081/ESE-120023373

Brame, J. A., \& Griggs, C. S. (2016). Surface area analysis using the Brunauer-Emmett-Teller (BET) method: scientific operation procedure series: SOP-C. https://hdl.handle.net/11681/20339

Burkhardt, W., \& Calci, K. R. (2000). Selective accumulation may account for shellfish-associated viral illness. Applied and Environmental Microbiology, 66(4), 1375-1378. https://doi.org/10.1128/AEM.66.4.1375-1378.2000

Chandrasekharan, N., \& Kamat, P. V. (2000). Improving the photoelectrochemical performance of nanostructured $\mathrm{TiO} 2$ films by adsorption of gold nanoparticles. The Journal of Physical Chemistry B, 104(46), 10851-10857. https://doi.org/10.1021/jp0010029

Deepracha, S., Vibulyaseak, K., \& Ogawa, M. (2019). Complexation of TiO2 with clays and clay minerals for hierarchically designed functional hybrids. In Advanced Supramolecular Nanoarchitectonics (pp. 125-150). William Andrew Publishing. https://doi.org/10.1016/B978-0-12-813341-5.00010-3

Deng, Y., Feng, C., Tang, L., Zeng, G., Chen, Z., \& Zhang, M. (2019). Chapter 5 - Nanohybrid photocatalysts for heavy metal pollutant control. In Nanohybrid and Nanoporous Materials for Aquatic Pollution Control (pp. 125-153). Elsevier. https://doi.org/10.1016/B978-0-12-814154-0.00005-0

Devi, R. (2010). Innovative technology of COD and BOD reduction from coffee processing wastewater using avocado seed carbon
(ASC). Water, Air, and Soil Pollution, 207(1), 299-306. https://doi.org/10.1007/s11270-009-0137-2

Dutta, A. K., Maji, S. K., \& Adhikary, B. (2014). y-Fe2O3 nanoparticles: an easily recoverable effective photo-catalyst for the degradation of rose bengal and methylene blue dyes in the waste-water treatment plant. Materials Research Bulletin, 49, 2834. https://doi.org/10.1016/j.materresbull.2013.08.024

Edelstein, A. S., \& Cammaratra, R. C. (Eds.). (1998). Nanomaterials: synthesis, properties and applications. CRC press. https://doi.org/10.1201/9781482268591

El-Saliby, I. J., Shon, H., Kandasamy, J., \& Vigneswaran, S. (2008). Nanotechnology for wastewater treatment: in brief. Encyclopedia of life support system (EOLSS), 7. https://www.eolss.net/Sample-Chapters/C05/E6-144-23.pdf

Fawell, J., \& Nieuwenhuijsen, M. J. (2003). Contaminants in drinking waterEnvironmental pollution and health. British medical bulletin, 68(1), 199-208. https://doi.org/10.1093/bmb/ldg027

Feka, D. P. (2017). adsorptive treatment of tannery effluent with granulated activated carbon. An MSc thesis submitted to the department of chemistry, college of sciences, Federal University of Agriculture Makurdi, Nigeria.

Ferroudj, N., Nzimoto, J., Davidson, A., Talbot, D., Briot, E., Dupuis, V., ... \& Abramson, S. (2013). Maghemite nanoparticles and maghemite/silica nanocomposite microspheres as magnetic Fenton catalysts for the removal of water pollutants. Applied Catalysis B: Environmental, 136, 9-18. https://doi.org/10.1016/j.apcatb.2013.01.046

Gubicza, J. (2012). 8 - Relationship between microstructure and hydrogen storage properties of nanomaterials. In J. Gubicza (Ed.), Defect Structure in Nanomaterials (pp. 301-332). Woodhead Publishing. https://doi.org/10.1533/9780857096142.301

Gupta, V. K., Khamparia, S., Tyagi, I., Jaspal, D., \& Malviya, A. (2015). Decolorization of mixture of dyes: a critical review. https://www.sid.ir/en/journal/ViewPaper.aspx?id=441797

Gupta, V. K., Tyagi, I., Sadegh, H., Ghoshekandi, R. S., \& Makhlouf, A. H. (2017). Nanoparticles as adsorbent; a positive approach for removal of noxious metal ions: a review. Science Technology and Development, 34(3),

195-214. https://doi.org/10.3923/std.2015.195.214

Itodo, A. U., Khan, M. E., \& Feka, D. P. (2017). On the adsorptive detoxification of chrome tan liquor: kinetics, thermodynamics and mode of transport. nature, 4, 5. https://doi.org/10.9734/AJOCS/2017/32728

Itodo, U., Khan, M., Feka, D., \& Ogoh, B. (2018). Tannery wastewater evaluation and remediation: Adsorption of trivalent chromium using commercial and regenerated adsorbents. Journal of Water Technology and Treatment Methods, 1(1), 1-105. https://doi.org/10.31021/jwt.20181105

Jarvis, P., Jefferson, B., \& Parsons, S. A. (2006). Floc structural characteristics using conventional coagulation for a high doc, low alkalinity surface water source. Water research, 40(14), $2727-$ 2737. https://doi.org/10.1016/j.watres.2006.04.024

Jiuhui, Q. U. (2008). Research progress of novel adsorption processes in water purification: a review. Journal of environmental sciences, 20(1), 1-13. https://doi.org/10.1016/S1001-0742(08)60001-7

Kansal, S. K., Lamba, R., Mehta, S. K., \& Umar, A. (2013). Photocatalytic degradation of Alizarin Red S using simply synthesized ZnO nanoparticles. Materials letters, 106, 385-389. https://doi.org/10.1016/j.matlet.2013.05.074

Krishna, Y. S., Sandhya, G., \& Babu, R. R. (2018). Removal of heavy metals $\mathrm{Pb}$ (II), Cd (II) and $\mathrm{Cu}$ (II) from waste waters using synthesized chromium doped nickel oxide nano 
particles. Bulletin of the Chemical Society of Ethiopia, 32(2), 225238. https://doi.org/10.4314/bcse.v32i2.4

Kumar, K. Y., Muralidhara, H. B., Nayaka, Y. A., Balasubramanyam, J., \& Hanumanthappa, H. (2013). Hierarchically assembled mesoporous $\mathrm{ZnO}$ nanorods for the removal of lead and cadmium by using differential pulse anodic stripping voltammetric method. Powder technology, 239, 208-216. https://doi.org/10.1016/j.powtec.2013.02.009

Kyzas, G. Z., \& Matis, K. A. (2015). Nanoadsorbents for pollutants removal: a review. Journal of Molecular Liquids, 203, 159-168. https://doi.org/10.1016/j.molliq.2015.01.004

Lubick, N., \& Betts, K. (2008). Silver socks have cloudy lining/Court bans widely used flame retardant. Environmental Science \& Technology; 42(11), 3910. https://doi.org/10.1021/es0871199

Mousavi, S. M., Mahjoub, A. R., \& Abazari, R. (2015). Green synthesis of $\mathrm{ZnO}$ hollow sphere nanostructures by a facile route at room temperature with efficient photocatalytic dye degradation properties. RSC advances, 5(130), 107378-107388. https://doi.org/10.1039/C5RA19507A

Nagpal, M., \& Kakkar, R. (2019). Use of metal oxides for the adsorptive removal of toxic organic pollutants. Separation and Purification Technology, 211, 522-539. https://doi.org/10.1016/j.seppur.2018.10.016

Oladipo, A. A., Adeleye, O. J., Oladipo, A. S., \& Aleshinloye, A. O. (2017). Bio-derived MgO nanopowders for BOD and COD reduction from tannery wastewater. Journal of water process engineering, 16,

142-148. https://doi.org/10.1016/j.jwpe.2017.01.003

Ramasami T., Rajamani S. and Raghava rao J. (2015). Pollution control in leather industry: Emerging technological options; Paper presented at the International Symposium on Surface and Colloidal Science and its elevance to soil pollution, Madras.

Rehman, A., \& Anjum, M. S. (2010). Cadmium uptake by yeast, Candida tropicalis, isolated from industrial effluents and its potential use in wastewater clean-up operations. Water, Air, and Soil Pollution, 205(1), 149-159. https://doi.org/10.1007/s11270009-0062-4

Rodríguez, C., Briano, S., \& Leiva, E. (2020). Increased Adsorption of Heavy metal ions in multi-walled carbon nanotubes with improved dispersion stability. Molecules, 25(14), 3106. https://doi.org/10.3390/molecules25143106

Sadegh, H., Shahryari-ghoshekandi, R., \& Kazemi, M. (2014). Study in synthesis and characterization of carbon nanotubes decorated by magnetic iron oxide nanoparticles. International Nano Letters, 4(4), 129-135. https://doi.org/10.1007/s40089-0140128-1

Saikia, I., Hazarika, M., \& Tamuly, C. (2015). Synthesis, characterization of bio-derived $\mathrm{ZnO}$ nanoparticles and its catalytic activity. Materials Letters, 161, 29-32. https://doi.org/10.1016/j.matlet.2015.08.068

Sarma, G. K., Gupta, S. S., \& Bhattacharyya, K. G. (2019). Nanomaterials as versatile adsorbents for heavy metal ions in water: a review. Environmental Science and Pollution Research, 26(7), 6245-6278. https://doi.org/10.1007/s11356018-04093-y

Sawyer, C.N., McCarty, P.L., \& Parkin, G.F. (2000). Chemistry for Environmental Engineering 4th Edition. Tata McGraw-Hill Publishing Company Limited.

Shamsizadeh, A., Ghaedi, M., Ansari, A., Azizian, S., \& Purkait, M. K. (2014). Tin oxide nanoparticle loaded on activated carbon as new adsorbent for efficient removal of malachite green-oxalate: non-linear kinetics and isotherm study. Journal of Molecular Liquids, 195,

212-218. https://doi.org/10.1016/j.molliq.2014.02.035

Singh, S., Barick, K. C., \& Bahadur, D. (2013). Fe 304 embedded ZnO nanocomposites for the removal of toxic metal ions, organic dyes and bacterial pathogens. Journal of Materials Chemistry A, 1(10), 3325-3333. https://doi.org/10.1039/c2ta01045c

Talam, S., Karumuri, S. R., \& Gunnam, N. (2012). Synthesis, characterization, and spectroscopic properties of $\mathrm{ZnO}$ nanoparticles. International Scholarly Research Notices, 2012. https://doi.org/10.5402/2012/372505

Tamuly, C., Hazarika, M., Das, J., Bordoloi, M., Borah, D. J., \& Das, M. R. (2014). Bio-derived CuO nanoparticles for the photocatalytic treatment of dyes. Materials Letters, 123, 202-205. https://doi.org/10.1016/j.matlet.2014.03.010

Theron, J., Walker, J. A., \& Cloete, T. E. (2008). Nanotechnology and water treatment: applications and emerging opportunities. Critical reviews in microbiology, 34(1), 43-69. https://doi.org/10.1080/10408410701710442

United Nations Industrial Development Organization (UNIDO) (2016). Pollutants in tannery effluents; sources, description, environmental impact.

Wei, X., Zhu, G., Fang, J., \& Chen, J. (2013). Synthesis, characterization, and photocatalysis of well-dispersible phasepure anatase $\mathrm{TiO} 2$ nanoparticles. International Journal of Photoenergy, 2013. https://doi.org/10.1155/2013/726872

Zare, K., Najafi, F., \& Sadegh, H. (2013). Studies of ab initio and Monte Carlo simulation on interaction of fluorouracil anticancer drug with carbon nanotube. Journal of Nanostructure in Chemistry, 3(1), 1-8. https://doi.org/10.1186/2193-8865-3-71

Liu, Z., Wu, Y., Chen, J., Li, Y., Zhao, J., Gao, K., \& Na, P. (2018). Effective elimination of As (iii) via simultaneous photocatalytic oxidation and adsorption by a bifunctional cake-like TiO 2 derived from MIL-125 (Ti). Catalysis Science \& Technology, 8(7), 1936-1944. https://doi.org/10.1039/C8CY00125A 